(C) 1980. The Genetical Society of Great Britain

\title{
MULTIPLE MATINGS, EFFECTIVE POPULATION SIZE AND SEXUAL SELECTION IN DROSOPHILA MELANOGASTER
}

\author{
C. PETIT, P. BOURGERON and H. MERCOT \\ Laboratoire de Génétique des Populations de l'Université Paris 7 , \\ Tour 42, 2 place Jussieu. 75005 Paris, France (*)
}

Received 27.ii.80

\section{SUMMARY}

\begin{abstract}
The distribution of sexually efficient males has been analysed in two populations made up of 5 times more females than males. When observation stops as soon as the number of inseminated females equals the number of males, 25 per cent of males in both strains had not mated, 50 per cent of the matings were performed by 50 per cent of the males who mated only once and the other 50 per cent of matings were performed by 25 per cent of the males who mated 2 or 3 times. Productivity of the successive matings falls drastically after the third mating. The relative role of sexual selection and multiple matings as components of fitness are discussed, as well as their implications for the effective population size.
\end{abstract}

\section{INTRODUCTION}

THE fact that males can mate with more than one female forms one of the bases for sexual selection, especially because females generally accept a limited number of mates. Manning (1962) reported that Drosophila melanogaster females will not mate in less than 2-day intervals, a time varying according to the strain and the species. Wheeler (1947) described the insemination reaction that prevents the female from mating immediately in many Drosophila species. Differences between male and female behaviour and the resulting sex-ratio bias are especially clear in some species of birds or mammals which need parental care, namely, sage grouse (Wiley, 1973, 1974), elephant seals (Le Boeuf, 1976; Cox and Le Boeuf, 1977) and baboons (de Vore, 1965).

Nevertheless, the ability of females to mate several times has been known for a long time in experimental populations of Drosophila melanogaster (Boesiger, 1957, 1962; Fukatami and Moriwaki, 1970; Fuerst et al., 1973; Milkman and Zeitler, 1974; Boulletreau-Merle, 1975), D. pseudoobscura (Dobzhansky and Pavlovsky, 1967) and D. paulistorum (Richmond and Ehrman, 1974).

More recently it has been demonstrated in natural populations of Drosophila, using alloenzymes: Anderson (1974) has reported a relatively high frequency of multiple insemination (40 per cent) in a sample of $D$. pseudoobscura collected from a natural population; Richmond and Powell (1970), studying $D$. paulistorum demonstrated that about 8 per cent of the females collected in the wild had mated at least twice; Milkman and Zeitler (1974) and Craddock and Johnson (1978) have found comparable results in $D$. melanogaster and $D$. silvestris respectively, Fountatou-Vergini in $D$. pseudoobscura (1973) and Zouros and Krimbas in Dacus oleae (1970).

\footnotetext{
*ERA 406 CNRS: "Analyse et mécanismes de maintien du polymorphisme".
} 
The consequences for evolution will be very different depending on whether or not the frequency of male and female multiple matings in a given species is the same or not. A difference will introduce a bias in the ratio of the sexes involved in reproduction; a fraction of the male population will be excluded from the reproductive pool. Unfortunately, male ability in multiple mating cannot be evaluated in nature. Nevertheless, Boesiger (1957, 1962 ) has shown in $D$. melanogaster that heterozygous males are able to inseminate more females than homozygous ones and Maynard Smith (1956) demonstrated that inbreeding in $D$. subobscura resulted in decreased “athletic ability". Lefevre and Johnson (1962) evaluated the productivity of the successive mates in laboratory stocks. But a synthesis of the two aspects had never been made. Moreover, another well known aspect of sexual selection is the ability to mate quickly, a behavioural trait related to sexual isolation and consequently important for speciation.

We decided to look at the different aspects of the problem: frequency, distribution and productivity of multiple matings in freshly collected populations of $D$. melanogaster. This was done in order to evaluate the effective male population size and then to examine the relation between multiple matings and sexual selection defined as the male ability to mate quickly.

\section{Material ANd methods}

Three wild strains Ampuis, Nago and Perols and a laboratory one $+i s o w$ have been used. Ampuis, from France (Burgundy) and Nago, from Japan, were initiated two years before the beginning of experiments from more than 50 pairs and Perols, from France (Languedoc) from 500 flies collected three months before the experiments. In the laboratory, all strains have been maintained in large populations to preserve their genetic variation. Electrophoretic analysis demonstrated that the average frequency of heterozygous individuals was 0.23 in Ampuis (Girard et al., 1977), but Perols and Nago were not assayed. The + iso $w$ strain has been kept for many years in the laboratory and was highly inbred and genetically monomorphic. The flies used for the experiments were kept at $25^{\circ} \mathrm{C} \pm 1$ on a maize medium in uncrowded conditions.

Two series of experiments were carried out: the first series to evaluate the number of one-male matings under competitive conditions, the second to measure the productivity of successive matings. In this latter series, we looked for a correlation between the number of matings and the premating time.

\section{(i) Evaluation of the number of one-male matings}

These experiments have been carried out with a great excess of females. Thus males mated as many times as they could despite the fact that $D$. melanogaster females rarely accept two consecutive copulations. Four males and 20 females of the same strain, kept separately for 4 days, were introduced without anaesthesia into a Elens-Wattiaux (1964) chamber and observed for 3 hours. Males were individually marked by wing margin excisions on the left, right, both wings or neither. Clipping, performed on very lightly anaesthetized flies at the same time as they were sexed after eclosion, does not affect the mating propensity of the marked individuals, as 
has been shown by Ehrman (1966), Petit et al. (1976) and confirmed in these experiments. Seven chambers were observed at the same time, and 8 series have been made, giving a total of 56 chambers for each strain.

Records were made of:

(a) the time at which any one mating takes place and comes to an end,

(b) the location of each pair in the chamber: mating pairs being generally motionless, the successive matings of the same male could be distinguished, even when the change of partner took place while the experimentor was looking at another cage,

(c) the type of male involved.

Several males could mate in the same time, which eventually allowed the stimuli emitted during copulation to lower the receptivity threshold of females and to increase male excitation. The experiments were performed either from 9 to 12 a.m. or from 5 to 8 p.m. but no statistically significant difference was demonstrated between morning and afternoon, and hence the results have been pooled.

\section{(ii) Productivity of successive matings of one male}

In order to eliminate female genetic heterogeneity, females of the strain + iso $w$ have been used. One Perols male and $4+i s o w$ females marked in the same way as males in the previous experiment, and kept separately, were introduced into reduced size Elens-Wattiaux chambers and observed for 3 hours. Thirteen series of experiments have been performed, each series including from 7 to 9 chambers and observed from 9 to 12 a.m. As soon as matings took place, the time and the type of females were recorded. At the end of every copulation which exceeded 5 minutes, the female was taken off, placed in an individual vial containing maize medium, and replaced by a virgin female marked in the same way. Every 2 or 3 days, the females were removed to a new vial until the 15 th day, in order to minimise larval competition for food in the vials. Thus all larvae were able to become adults and the total female productivity could be recorded. This kind of experiment did not allow stimulation by the other mating pairs. Nevertheless, it was used as the only possible way to measure the productivity of males in successive matings. The variability of female productivity was reduced as genetic variability was low and the environment highly constant.

Final female sterility was estimated by placing potentially sterile females, i.e., those that had not mated within 10-12 days with 2 or 3 males. Recorded sterility was very low ( 2 among 196 for the first 42 tested males) and so finally neglected. Females who died before the 10 th day have not been taken into account; the delay was shortened to 6 days for the 5 th or higher rank matings because the females inseminated in these ranks do not give offspring after the 6 th day.

\section{Results}

Four different questions were considered:

(1) How many females could be inseminated by one male in a 3-hour observation period? 
(2) What was the distribution of matings recorded as soon as the number of inseminated females equalled the number of males?

(3) Did the successive matings of one male produce the same number of offspring? (Lefevre and Johnson (1962) have attempted to answer this, but they used old laboratory strains whose performance might be quite different from freshly captured ones.)

(4) Was there any correlation between the number of matings and premating time?

\section{(i) How many females could be inseminated in a 3-hour period?}

The results are given in table 1 and fig. 1. In Ampuis and Nago strains about 15 per cent of males had not mated in a total of 227 and 236 males examined per strain. Males that mated once (13 per cent and 20 per cent of the males in Ampuis and Nago respectively) inseminated 6 and 10 per cent of the females, while males that copulated three times or more ( 49 and 36 per cent respectively of the males) inseminated 77 and 62 per cent of the females. In Perols, all males had mated; but these results cannot be taken into account, since the observation method excluded male competition, quite an artificial situation.
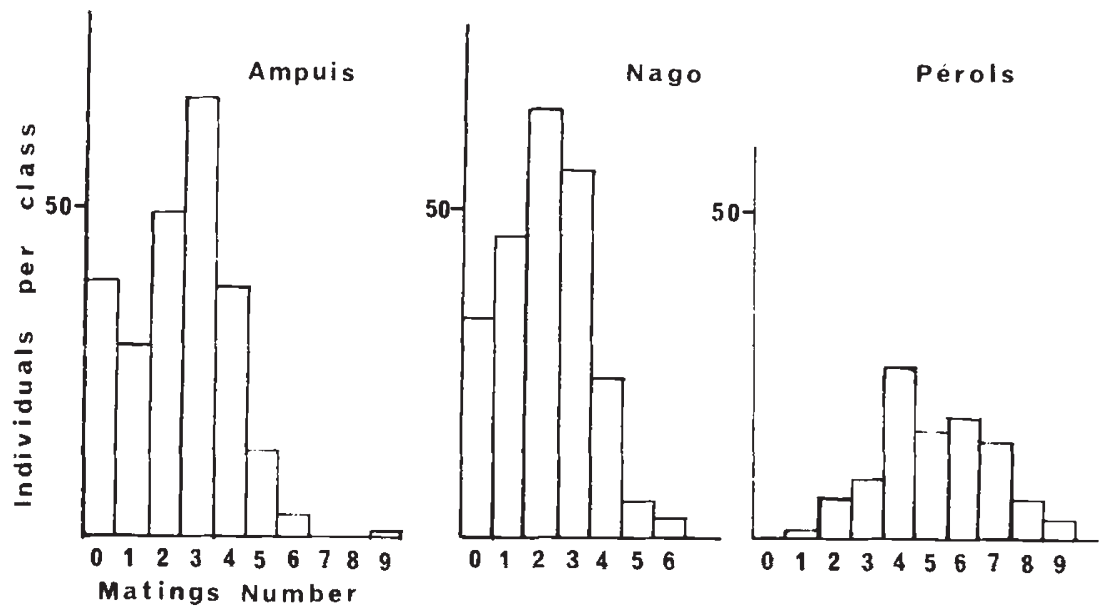

FIG. 1-Distribution of male matings in three strains of Drosophila melanogaster after a three-hour contact.

The question that arose then was whether the absence of one or multiple matings was a result due to chance or to male vigour differences. The evolutionary implications of the answer are important because only the second hypothesis implies selection of the most vigorous males, the number of matings influencing fitness. A comparison of the two distributions with a Poisson distribution allowed us to choose between the two hypotheses. In the Ampuis strain, $\chi^{2}$ is highly significant $\left(\chi^{2}=30.8\right.$ for 4 d.f., the males mating 5, 6 and 9 times being grouped in one class); in Nago, it is at the limit of significance $\left(\chi^{2}=9.4\right.$ for 4 d.f., $\left.p=0 \cdot 052\right)$. It seems most likely that the number of matings is not random in our experiment. 
TABLE 1

Distribution of male matings in Drosophila melanogaster in Ampuis and Nago strains

After a 3-hour observation period

\begin{tabular}{|c|c|c|c|c|c|}
\hline $\begin{array}{l}\text { Number of } \\
\text { matings } \\
\text { per male }\end{array}$ & $\begin{array}{l}\text { Number of } \\
\text { individuals } \\
\text { per class }\end{array}$ & Frequency & $\begin{array}{l}\text { Matings } \\
\text { number } \\
\text { per class }\end{array}$ & $\begin{array}{l}\text { Mating } \\
\text { frequency } \\
\pm \text { s.e. }\end{array}$ & $\begin{array}{c}\text { Rough } \\
\text { productiv } \\
\text { per matin } \\
\text { No. }\end{array}$ \\
\hline \multicolumn{6}{|c|}{ Ampuis } \\
\hline 0 & 39 & 0.17 & 0 & 0 & 0 \\
\hline 1 & 30 & 0.13 & 30 & $0.06 \pm 0.01$ & $0 \cdot 13$ \\
\hline 2 & 47 & $0 \cdot 21$ & 94 & $0.18 \pm 0.04$ & 0.39 \\
\hline 3 & 57 & $0 \cdot 25$ & 171 & $0.32 \pm 0.04$ & 0.48 \\
\hline 4 & $37)$ & & 148 & & \\
\hline 5 & 13 & 0.24 & 65 & $0.45 \pm 0.03$ & $\neq \neq 0$ \\
\hline 6 & 3 & & 18 & & \\
\hline 9 & 1 & & 9 & & \\
\hline & 227 & & 535 & & \\
\hline \multicolumn{6}{|c|}{ Nago } \\
\hline 0 & 38 & 0.16 & 0 & 0 & 0 \\
\hline 1 & 48 & $0 \cdot 20$ & 48 & $0 \cdot 10 \pm 0.01$ & $0 \cdot 16$ \\
\hline 2 & 65 & 0.28 & 130 & $0.28 \pm 0.02$ & 0.45 \\
\hline 3 & 54 & 0.23 & 162 & $0.34 \pm 0.04$ & 0.39 \\
\hline 4 & $23)$ & & 92 & & \\
\hline 5 & $5\}$ & $0 \cdot 13$ & 25 & $0 \cdot 28 \pm 0 \cdot 04$ & $\neq \neq 0$ \\
\hline \multirow[t]{2}{*}{6} & 3) & & 18 & & \\
\hline & 236 & & 475 & & \\
\hline
\end{tabular}

"Limited matings"

$\begin{array}{ccccc}\begin{array}{c}\text { Number of } \\ \text { matings } \\ \text { per male }\end{array} & \begin{array}{c}\text { Number of } \\ \text { individuals } \\ \text { per class }\end{array} & \begin{array}{c}\text { Frequency } \\ \text { Ampuis }\end{array} & \begin{array}{c}\text { Matings } \\ \text { number } \\ \text { per class }\end{array} & \begin{array}{c}\text { Mating } \\ \text { frequency } \\ \pm \text { s.e. }\end{array} \\ 0 & 61 & 0.27 & 0 & \\ 1 & 111 & 0.49 & 111 & 0.49 \pm 0.03 \\ 2 & 49 & 0.21 & 98 & 0.43 \pm 0.03 \\ 3 & 6 & 0.03 & 18 & 0.08 \pm 0.02 \\ & 227 & & 227 & \\ 0 & & & & \\ 1 & 52 & 0.22 & 0 & \\ 2 & 132 & 0.56 & 126 & 0.56 \pm 0.03 \\ 3 & 50 & 0.21 & 92 & 0.41 \pm 0.03 \\ & 2 & 0.01 & 6 & 0.03 \pm 0.01 \\ & 236 & & 224 & \end{array}$

(ii) Did all males mate in a population with a $1: 1$ sex ratio?

The distribution of matings performed when the number of inseminated females equals the number of males was analysed in Ampuis and Nago. (Perols was not taken in account because the method eliminated male competition.) The results were supposed to be nearer those existing in natural or experimental populations, where the sex ratio is close to $1: 1$. They are designated as "limited matings" (table 1 and fig. 2). During these experiments, about 25 per cent of the males did not mate, 50 per cent of the 


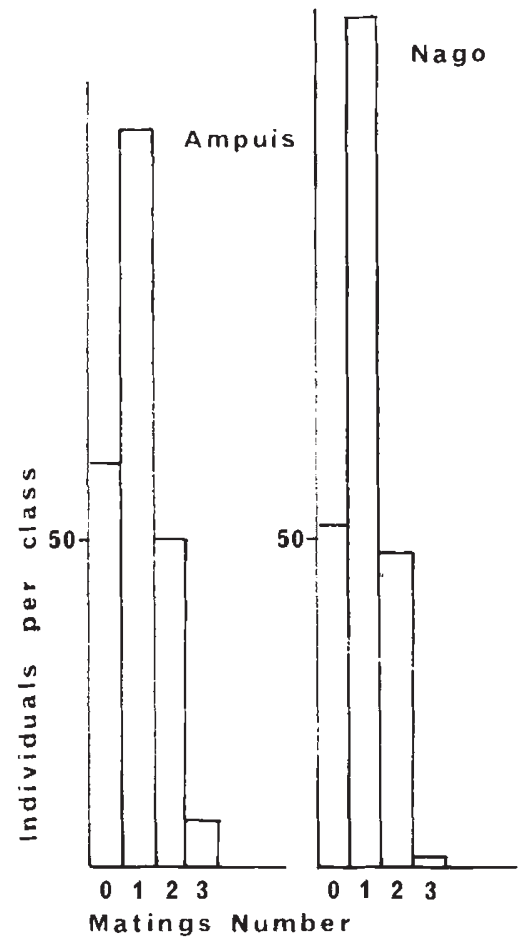

FIG. 2-Distribution of male matings in two strains of Drosophila melanogaster. The experiments were stopped when the number of inseminated females equalled the number of males ("Limited matings").

matings were performed by 50 per cent of the males who mated only once, and the other 50 per cent of the matings were performed by 25 per cent of the males who mated two or three times. The percentages are not exactly the same in the two strains but they are very close. In any case, it is clear that the male effective population size is different from the male population size.

(iii) Do the successive matings of one male produce the same number of offspring?

In Ampuis and Nago strains, the duration of the copulation was not drastically different in the first successive matings (table 2). But this result does not prove that productivity is the same in the case of successive matings. Productivity was measured in Perols (table 3 and fig. 3). It falls significantly from the first 3 matings to the fourth, the first 3 matings producing 92.66 per cent of the total number of offspring.

\section{TABLE 2}

Length in minutes of the successive matings in Ampuis and Nago (followed by its standard error)

\begin{tabular}{ccccccr} 
Correlation rank & 1 & 2 & 3 & 4 & 5 & \multicolumn{1}{c}{6} \\
Ampuis & $17 \cdot 9 \pm 0.9$ & $15 \cdot 7 \pm 0.9$ & $16 \cdot 1 \pm 1 \cdot 2$ & $15 \cdot 9 \pm 0.9$ & $16 \pm 2 \cdot 7$ & $16 \cdot 5 \pm 3 \cdot 5$ \\
Nago & $18 \cdot 5 \pm 0 \cdot 6$ & $15 \cdot 7 \pm 0.8$ & $15 \cdot 8 \pm 0 \cdot 8$ & $16 \cdot 1 \pm 1 \cdot 7$ & $12 \cdot 9 \pm 3 \cdot 5$ & $12 \pm 6.6$
\end{tabular}


TABLE 3

Productivity related to mating rank in Perols

Mating rank

No. individuals per class

Mean productivity per rank

Percentage progeny among total progeny
Standard error

$\begin{array}{rcccccccc}1 & 2 & 3 & 4 & 5 & 6 & 7 & 8 & 9 \\ 97 & 90 & 90 & 85 & 59 & 43 & 24 & 9 & 3 \\ 313.8 & 273.6 & 194.2 & 64 & 9.1 & 2.7 & 1.5 & 0.8 & 0 \\ 9.1 & 10 & 9.5 & 7.7 & 2.2 & 0.9 & 0.9 & 0.8 & \\ 36.5 & 31.8 & 22.6 & 7.4 & 1.1 & 0.3 & 0.2 & 0.1 & \end{array}$

It can easily be seen that the first two matings produce about the same number of flies, while the third produces only $\frac{2}{3}$ of the number of offspring of the first mating. This result does not invalidate Lefevre and Johnson's results (1962); the better productivity observed in the Perols strain for the third mating compared to that of Lefevre's strain is certainly due to the difference in genetic heterozygosity between these two strains: Perols is nearly a natural strain while that of Lefevre is a laboratory one. According

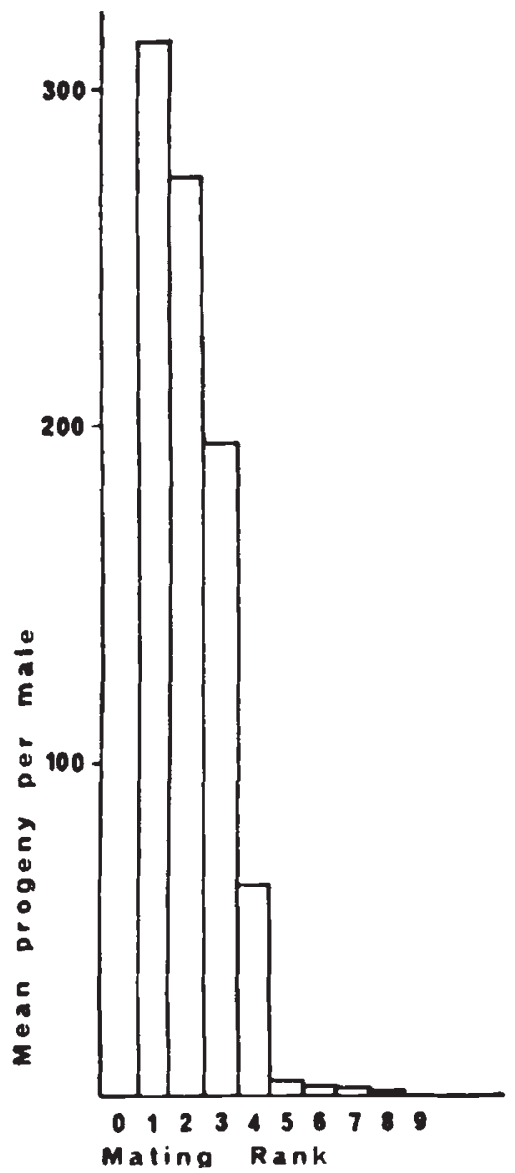

FIG. 3.-Progeny related to mating rank in Perols strain. 
to Lefevre and Johnson the absence of sperm transfer after the third mating results from the fact that accessory glands are completely empty.

Consequently the results obtained from those matings in which males do not mate more than 3 times need only a slight correction for the third mating whose productivity is multiplied by $\frac{2}{3}$. Those obtained after a 3 -hour period however have to be greatly modified, the 4 th, 5 th and following matings being negligible as far as productivity is concerned (table 1, column 6).

\section{(iv) Is there any correlation between the number of matings and the premating time?}

The method used to measure productivity in relation to the rank of copulation allowed us to answer this question. Fulker (1966) states that males which "mate on the first occasion also copulate more often, more successfully"; but nobody else has investigated the question in spite of its importance. We have calculated the correlation between number of matings and premating time by a rank correlation test of Spearman. But a bias could result from the experimental method: the length of copulation is about 20 minutes, thus males whose first mating takes place after 20 minutes can mate 8 times at best for the 3 -hour period of observation; if they mate for the first time after 40 minutes, only 7 matings are at best possible for them, and so on. The correlation has been calculated among males who mated before 20 minutes and for those who mated before 40 minutes (table $4 \mathrm{AB}$ ) and it is

\section{TABLE 4}

Correlation between number of matings and premating time in Perols. A: for males whose first mating took place before 20 minutes, $B$; before 40 minutes. The correlation coefficient has been calculated by a Spearman test

\begin{tabular}{|c|c|c|c|c|}
\hline \multirow[b]{2}{*}{ Matings number } & \multicolumn{2}{|c|}{ A } & \multicolumn{2}{|r|}{ B } \\
\hline & Males No. & $\begin{array}{l}\text { ean premating } \\
\text { time }\end{array}$ & Males No. & $\begin{array}{c}\text { Mean premating } \\
\text { time }\end{array}$ \\
\hline 9 & 3 & $2 \cdot 66$ & & \\
\hline 8 & 6 & $2 \cdot 66$ & 9 & $2 \cdot 66$ \\
\hline 7 & 15 & $3 \cdot 33$ & 15 & $3 \cdot 33$ \\
\hline 6 & 21 & $4 \cdot 00$ & 21 & $4 \cdot 00$ \\
\hline 5 & 15 & $5 \cdot 60$ & 15 & $5 \cdot 60$ \\
\hline 4 & 21 & $5 \cdot 38$ & 23 & $7 \cdot 56$ \\
\hline 3 & 7 & $4 \cdot 28$ & 8 & $7 \cdot 37$ \\
\hline 2 & 2 & $4 \cdot 50$ & 3 & $10 \cdot 00$ \\
\hline 1 & 1 & 6.00 & 1 & $6 \cdot 00$ \\
\hline $\begin{array}{l}\text { Correlation } \\
\text { coefficient }\end{array}$ & $\mathrm{r}=0.833^{* *}$ & with $n=9$ & $r=0.833$ & with $n=8$ \\
\hline
\end{tabular}

significant in both cases. Those who mate first mate the most. The results are the same under competition during a three hour contact, for Ampuis and Nago (table 5), the correlation being very high $(r=0.9762$ with $n=8$ in Ampuis and $r=1$ with $n=7$ in Nago)*

\footnotetext{
* The detailed data are available from the authors.
} 
TABLE 5

Correlation between number of matings and premating time in Ampuis and Nago calculated by a Spearman test

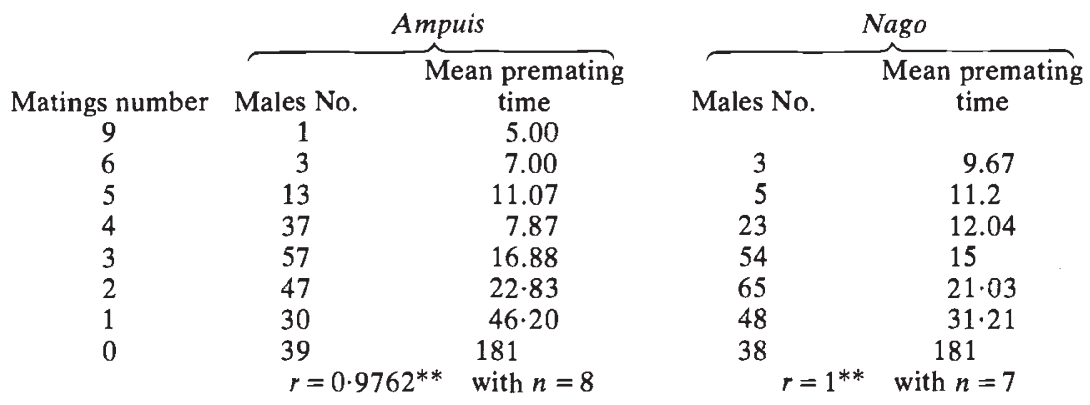

** Significant at the 0.01 level.

\section{Discussion}

Three major conclusions can be derived from these experiments:

(a) In the strains studied under competitive conditions, 25 per cent of males do not succeed in contributing to the following generation; the other 75 per cent contribute unequally because of the different numbers of matings.

(b) The productivity of males is not proportional to the number of matings, the fourth one being practically sterile in the newly captured strain assayed.

(c) There is a correlation between the number of matings and the precopulating time.

It is quite probable that the differences between the number of matings of different males were not random. Boesiger $(1957,1962)$ demonstrated that heterozygous males inseminated more females than did homozygous males, but it was not certain that the heterozygosity level of the different males of a population would be different enough to result in different numbers of matings; those might be random. Our results-the departure from a Poisson distribution-demonstrate that it is not a random phenomenon and that multiple matings result probably from individual physiological characteristics such as Maynard Smith's "athletic ability". Then, this sexual vigour has surely an adaptive function, either to multiply the best genotypes, or, taking into account the correlation between sexual vigour and heterozygosity, to contribute to the maintenance of genetic polymorphism. In fact, it would be necessary to repeat the third experiment, looking for a correlation between male heterozygosity as revealed by allozymes and sexual vigour; unfortunately we have not had the opportunity to analyse a sufficiently large number of loci to obtain significant results. In any case it is likely that the multiple mating ability in Drosophila, as in the elephant seal (Le Boeuf, 1976), results from a selective process.

Coming back to Drosophila, the ability to engage in several matings makes it necessary to reconsider the definition and the nature of sexual selection. Many experiments have demonstrated that in a population with a 
normal sex ratio, observed during a sufficiently short time to prevent multiple matings, the mating probability is different for the different types of males, whatever the kind of difference studied: mutation of a morphological gene, inversion or geographic origin (for a detailed review see Petit and Ehrman, 1970 and Spiess, 1970). Sexual selection implies "the power of males to charm females" as well as female receptivity to a given male. It is due to the efficiency of emitted and received stimuli; and its basis is essentially ethological. The sexual vigour demonstrated in our experiments is something else, probably closely linked to the male general vigour, to their ability to vibrate wings for long periods and a great number of times. Assaying simultaneously sexual selection and sexual vigour in homozygous and heterozygous lines of different white and wild strains, we have demonstrated (Faugères et al., 1971), that the order of increasing advantage is not the same for the two phenomena: in these strains, white phenotype was always at a disadvantage in sexual selection, while in sexual vigour, the disadvantaged form was always the homozygous one, whether white or wild.

While multiple matings and sexual selection are not specifically laboratory phenomena, their importance as components of fitness can be evaluated only in experimental populations; but examples are rare. Equal importance of sexual selection (including male vigour) and egg-to-adult viability has been demonstrated in populations of Drosophila melanogaster including the mutation Bar and its wild type allele (Petit, 1951; Ribo, 1977). But in populations of the same species including sepia and its wild type allele, sexual selection (measured after a time short enough to eliminate multiple matings), had a smaller influence than viability (Anxolabéhère, 1980). A study of selection components in the dynamics of a fourth chromosome polymorphism in an experimental population of Drosophila melanogaster (Bundgaard and Christiansen, 1972) demonstrated the main role of sexual selection measured in such a way that male vigour was eliminated; Spiess and Langer (1961) and later Sherwin and Spiess (1973) have demonstrated the behavioural basis of the adaptive role of chromosomal polymorphism in Drosophila persimilis and Drosophila pseudoobscura. Marinkovic and Ayala (1975) have demonstrated an influence of male mating capacity in selection at the Pgm and Me 2 loci in Drosophila pseudoobscura while Snyder and Ayala (1979) did not find any influence at the Mdh 2 and Pgm 1 loci of other strains. On the contrary, Palabast (1980) demonstrated an important role of viability but no influence of sexual selection in the dynamics of the $\alpha$-Gpdh locus in Drosophila melanogaster. Therefore, the importance of sexual behaviour sensu lato as a component of fitness varies from one locus to another. But even when it is known, the importance of sexual selection sensu stricto (measured by short contact periods) and sexual vigour (defined as ability for multiple matings) are not clearly analysed. The agreement of results obtained by the different techniques leads us to believe that a correlation between the two exists as a result of natural selection, a hypothesis that is confirmed by Fulker and ourselves. Perhaps, to be precise, sexual selection sensu stricto would have to be considered as sexual selection and male vigour as a component of natural selection. Whatever the answer, the two phenomena have a fundamental influence in the evolutionary process in view of their role in the maintenance of polymorphism, either in the case of sexual selection with the advantage of the rare type (Petit, 1951, 
1954, 1958; Ehrman, 1966; for a review see Petit, 1974), or in the case of male vigour as one of the aspects of heterosis (Boesiger, 1962).

Acknowledgments. - We thank Drs Anxolabéhére, Goux, Krimbas and Powell for their helpful comments and criticism of the manuscript and Dr Kovoor who kindly supervised the translation.

\section{REFERENCES}

ANDERSON, W.w. 1974. Frequent multiple insemination in a natural population of Drosophila pseudoobscura. Am. Nat., 108, 709-711.

ANXOLABEHERE, D, 1980. The influence of sexual and larval selection on the maintenance of polymorphism at the sepia locus in Drosophila melanogaster. Genetics, (in press).

BOESIGER, E. 1957. Sur l'activité sexuelle de plusieurs souches de Drosophila melanogaster. C.R. Acad. Sci., Paris, 244, 1419-1422.

BOESIGER, E. 1962. Sur le degré d'hétérozygotie des populations naturelles de Drosophila melanogaster et son maintien par la sélection sexuelle. Bull. Biol., 96(1), 1-121.

BOULLETREAU-MERLE, J. 1975. Influence de l'accouplement sur la physiologie reproductrice des femelles de Drosophila melanogaster. Thèse de l'Université Claude Bernard (Lyon).

BUNDGAARD, J., AND CHRISTIANSEN, F. B. 1972. Dynamics of polymorphisms: I. Selection components in an experimental population of $D$. melanogaster. Genetics, 71, 439-460.

COX, C. R., AND LE BÓEUF, B. J. 1977. Female incitation of male competition: a mechanism in sexual selection. Am. Nat., 111, 317-335.

CRADDOCK, E. M., AND JOHNSON, W. E. 1978. Multiple insemination in natural populations of Drosophila silvestris. D.I.S., 53, 138.

DE VORE, I. 1965. Male dominance and mating behavior in baboons. In Sex and behavior, ed. F. A. Beach, Wiley, New York.

DOBZHANSKY, TH, AND PAVLOVSKY, O. 1967. Repeated mating and sperm mixing in Drosophila pseudoobscura. Am. Nat., 101, 527-533.

EHRMAN, L. 1966. Mating success and genotype frequency in Drosophila. An. Behav., 14, 332-339.

ELENS, A. A., AND WATTIAUX, J. M. 1964. Direct observation of sexual isolation. D.I.S., 39, 118-119.

FAUGERES, A., PETIT, C., AND THIBOUT, E. 1971. The components of sexual selection. Evolution, 25, 265-273.

FOUNTATOU-VERGINI, J. 1973. Is Drosophila subobscura monogenic? D.I.S., 50, 101.

FUERST, P. A., PENDlebury, W. W., AND KidWEll, J. F. 1973. Propensity for multiple mating in Drosophila melanogaster female. Evolution, 27, 265-288.

FUKATAMI, A., AND MORIWAKI, D. 1970. Selection for sexual isolation in Drosophila melanogaster by a modification of Koopman's method. Jap. J. Genet., 45, 193-204.

FULKER, D. W. 1966. Mating speed in males of Drosophila melanogaster: a psychogenetic analysis. Science, 153, 203-205.

GIRARD, P., PALABOST, L., AND PETIT, C. 1977. Enzyme variation at 7 loci in 15 natural populations of Drosophila melanogaster. Bioch. Genet. 15, 589-599.

LE BOEUF, B. J. .1976. Male competition and reproductive success in elephant seals. Am. Zool., 14, 163-176.

LEFEVRE, G., AND JOHNSON, U. B. 1962. Sperm transfer, storage, displacement and utilization in Drosophila melanogaster. Genetics, 47, 1719-1736.

MANNING, A. 1962. A sperm factor affecting the receptivity of Drosophila melanogaster female. Nature, 194, 253-254.

MARINKOVIC, D., AND A YALA, F. J. 1975. Fitness of allozyme variants in D. pseudoobscura. I. selection at the Pgm-1 and $M E-2$ loci. Genetics, 79, 85-95.

MAYNARD SMITH, J. 1956. Fertility, mating behaviour and sexual selection in Drosophila subobscura. J. Genet., 54, 261-279.

MILKMAN, R., AND ZEITLER, R. R. 1974. Concurrent multiple paternity in nature and laboratory populations of Drosophila melanogaster. Genetics, 78, 1191-1193.

PALABOST, L. 1980. The maintenance mechanism of polymorphism at the $\alpha-G p d h$ locus in Drosophila melanogaster. Bioch. Genet., 18, 9, in press.

PETIT, C. 1951. Le rôle de l'isolement sexuel dans l'évolution des populations de Drosophila melanogaster. Bull. Biol., 85, 392-418. 
PETIT, C. 1954. L'isolement sexuel chez D. melanogaster. Etude du mutant white et de son allélomorphe sauvage. Bull. Biol., 88, 435-443.

PETIT, C. 1958. Le déterminisme génétique et psychophysiologique de la compétition sexuelle chez D. melanogaster. Bull. Biol., 92, 248-329.

PETIT, C. 1974. L'avantage du rare, facteur de maintien du polymorphisme. In "Le polymorphisme dans le règne animal, Lamotte Ed., Mémoire Soc. Zool. Fr., 417-442.

PETIT, C., AND EHRMAN, L. 1970. Sexual selection in Drosophila. Evolutionary Biology, 3, 117-223. ed. Dobzhansky, Hecht and Steere, Meredith corporation.

PETIT, C., KITAGAWA, O., AND TAKAMURA, T. 1976. Mating system between Japanese and French geographic strains of Drosophila melanogaster. Jap. J. Genet., 51, 99-108.

RIBO, G. 1977. Mécanisme du maintien de l'allèle Bar dans une population expérimentale de Drosophila melanogaster. Arch. Zool. Exp., 118(4), 375-389.

RICHMOND, R. C., AND EHRMAN, L. 1974. The incidence of repeating mating in the super-species Drosophila paulistorum. Experientia, 30, 489-490.

RICHMOND, R. C., AND POWELL, J. R. 1970. Evidence of heterosis associated with an enzyme locus in a natural population of Drosophila. Proc. Nat. Acad.Sci. U.S.A., 67, 1264-1267.

SHERWIN, R. N., AND SPIESS, E. B. 1973. Chromosomal control of mating activity in $D$. pseudoobscura. Proc. Nat. Acad. Sci. U.S.A., 70(2), 459-461.

SNYDER, T. P., AND AYALA, F. J. 1979. Temperature and density effects on fitness at the Mdh-2 and Pgm-1 loci of D. pseudoobscura. Genetica, 51(1), 59-67.

SPIESS, E. B. 1970. Mating propensity and its genetic basis in Drosophila. Essays in evolution and genetics in honor to Th. Dobzhansky, ed. Hecht and Steere, Appleton Century Crofts, N.Y.

SPIESS, E. B., AND LANGER, B. 1961. Chromosomal adaptive polymorphism in D. persimilis. III. Mating propensity of homokaryotypes. Evolution, 15,(4), 535-544.

WHEELER, M. R. 1947. The insemination reaction in intraspecific mating of Drosophila. Univ. of Texas Public. 4720, 78-115.

WILEY, R. H. 1973. The street display of male sage grouse: a "fixed" action pattern. Behaviour, 47, 129-152.

WILEY, R. H. 1974. Evolution of social organisation and life history pattern among grouse. $Q$. Rev. Biol., 49, 201-227.

ZOUROS, E., AND KRIMBAS, C. B. 1970. Frequency of female digamy in a natural population of the olive fruitfly Dacus oleae as found by using enzyme polymorphism. Entomologia experimentalis, 13, 1-9. 